\title{
Predictors of Photic Phenomena with a Trifocal IOL
}

This article was published in the following Dove Press journal:

Clinical Ophthalmology

\author{
Arnaldo Espaillat (iD) \\ Constanca Coelho (iD) ${ }^{2}$ \\ Michael J Medrano Batista' \\ Obniel Perez iD ${ }^{\prime}$ \\ 'Anterior Segment Department, Instituto \\ Espaillat Cabral, Santo Domingo, \\ Dominican Republic; ${ }^{2}$ Lisbon Medical \\ School, University of Lisbon, Lisbon, \\ Portugal
}

Aim: To assess predictive factors associated with glares and halos in patients undergoing cataract surgery with PanOptix trifocal IOL implantation.

Methods: Single-center retrospective study. One hundred and forty eyes from 70 patients with cataract were bilaterally implanted with a trifocal PanOptix aspherical diffractive lens between 2017 and 2019 and followed-up for six months. All patients were evaluated for refraction, corneal topography, and aberrometry pre- and post-operatively. Patients were assessed at 1 day, 6 days, 1 and 6 months after surgery. One and six months postoperatively patients were asked to complete a satisfaction questionnaire that included photic phenomena assessment. Main outcome measures were photic phenomena at 1 and 6 months of follow-up. Predictors of photic phenomena at 1 and 6 months were also analyzed.

Results: A higher corneal coma was associated with more mild halos at 6 months with no association regarding other degrees of severity. The lower the age the higher the glare or halos, the higher the lens thickness and the lower the anterior chamber depth or chord $\mu$ the less halos at 1 month. A significant proportion of patients had more none/mild compared to moderate/severe glare and halos both at 1 and 6 months post-operatively. Baseline BCVA was the only predictor of halos at 1 month and glare and halos at 6 months post-surgery.

Conclusion: On multivariate regression analyses, the only predictor of photic phenomena was baseline visual acuity, suggesting that patients that have a better visual acuity before surgery are more demanding regarding visual outcomes after surgery.

Keywords: cataract surgery, PanOptix trifocal IOL, predictors of photic phenomena

\section{Introduction}

Multifocal lenses offer the possibility of spectacle-free vision and this could be a motivation for the use of multifocal IOLs instead of monofocal IOLs. ${ }^{1,2}$ Nevertheless, the association of multifocal IOLs with photic phenomena remains one of the major causes of complaint after surgery. ${ }^{1,2}$

Pseudophakic photic phenomena are characterized by nonuseful patterns projected onto the retina in positive forms. These photic phenomena refer to bright artifacts that are only present in certain light conditions and produce images as glares and/or halos. ${ }^{3}$

Trifocal IOLs were designed to provide near, intermediate, and distance visual performances and increase spectacle independence. ${ }^{4}$ AcrySof $^{\circledR}$ IQ PanOptix ${ }^{\mathrm{TM}}$ (Alcon Laboratories, Inc., Fort Worth, TX, USA) is a nonapodized diffractive trifocal IOL that distributes light energy to three focal points in both small and large pupil conditions. Photic phenomena of multifocal IOLs, such as halos and glare, vary between patients ${ }^{1}$ with some continuing to experience pseudophakic
Correspondence: Arnaldo Espaillat Instituto Espaillat Cabral, Av. Independencia 853, Zona Universitaria, Santo Domingo, Dominican Republic Tel +I-809-686-0268

Email arnaldo@espaillatcabral.com 
photic phenomena ${ }^{5}$ many months after surgery. In this study, we assessed factors associated with glares and halos in patients with PanOptix IOL implantation.

\section{Patients and Methods Study Population}

This was a single-center retrospective study, performed at Instituto Espaillat Cabral, Dominican Republic, between September 2017 and February 2019, which included a study population of 140 eyes from 70 patients undergoing cataract surgery with bilateral implantation of a trifocal PanOptix lens.

Inclusion criteria: age $\geq 45$ years old; patients that wanted to have good vision most of the time without glasses at all distances; highest limit of mesopic pupil of $6 \mathrm{~mm}$; corneal total higher-order aberration $(\mathrm{HOA}) \leq 0.5 \mu \mathrm{m}$; corneal spherical aberration $\leq 0.3 \mu \mathrm{m}$; corneal coma $\leq 0.4 \mu \mathrm{m}$; corneal trefoil $\leq 0.3 \mu \mathrm{m}$; and angle kappa $\leq 0.58 \mathrm{~mm}$. Exclusion criteria: patients with moderate or severe dry eye syndrome; any ocular pathology other than cataract or any systemic condition that, in the investigators' opinion, could compromise the efficacy or safety of surgery; eyes with surgical complications or posterior capsular opacification that required an $\mathrm{Nd}$ :YAG laser capsulotomy; patients unwilling or unable to provide informed consent; patients with type A personality and/or unreal post-surgical visual expectations.

This study was conducted in agreement with the tenets of the declaration of Helsinki in its latest amendment (Brazil, 2013). All patients signed an informed consent form and the study was approved by the Ethics Committee of Instituto Espaillat Cabral. No patientprotected data were collected or reported.

\section{The Trifocal PanOptix Lens}

This is a single-piece hydrophobic IOL that is based on a quadrifocal optical principle. It is designed to have an intermediate focal point of $60 \mathrm{~cm}$ (arms-length) and an optimal close reading distance at $42 \mathrm{~cm}$. The light efficiency of the IOL has been measured at $88 \%$ at a $3.0 \mathrm{~mm}$ pupil size. ${ }^{6,7}$ This IOL comes in a toric and non-toric version.

\section{Surgical Procedure}

All surgeries were performed by the same surgeon (AE) and were done either by standard phacoemulsification with the Centurion ${ }^{\circledR}$ Vision System (Alcon Laboratories, Inc.), or assisted with femtosecond laser (LenSx ${ }^{\circledR}$; Alcon
Laboratories, Inc.). The same patient had both their eyes operated within a week.

\section{Assessments}

Pre-operatively all patients underwent a comprehensive ophthalmic history and examination including tear osmolarity test (Tearlab Corporation, San Diego, CA, USA), corneal topography, and aberrometry (OPD-scan III, Nidek Co Ltd., Gamagori, Japan), biometry (IOLMaster 700, Carl Zeiss Meditec AG, Jena, Germany), specular microscopy (CEM 539, Nidek Co Ltd.), and macular and papillary Optical Coherence Tomography (Cirrus $4000 \mathrm{Hd}$ OCT, Carl Zeiss Meditec AG). Patients who had a preoperative keratometric astigmatism $\geq 0.7 \mathrm{D}$ against-the-rule or $\geq 1.0 \mathrm{D}$ with-the-rule were corrected with a toric IOL. The Barrett universal II formula was used to calculate the spherical power of the lens and the Barrett's formula for toric lenses was used to calculate the cylindrical power.

Patients were assessed at 1 day, 6 days, 1 and 6 months after surgery. One and six months post-operatively, refraction, corneal topography, and aberrometry were performed and patients were asked to complete a satisfaction questionnaire including photic phenomena (Supplementary file 1). The presence of posterior capsular opacity was also assessed.

Manifest refraction, both corrected and uncorrected far and near visual acuity, pre-operative corneal aberration as well as post-operative total ocular and corneal aberration measurements, biometric values, and satisfaction questionnaire data were tabulated. Visual acuity data were recorded in Snellen notation but converted to logarithm of the minimum angle of resolution (logMAR) for analytical purposes. Data were analyzed pre-operatively and after surgery at 1 and 6 months of follow-up.

\section{Outcomes}

Main outcome measures were photic phenomena at 1 and 6 months of follow-up. We have also analyzed if any of the following pre-surgical parameters could be associated with photic phenomena in patients with PanOptix IOL implantation: mesopic pupil, angle kappa, total ocular and corneal higher-order aberrations, coma, trefoil, spherical aberration, corneal surface regularity index (SRI), and corneal irregular astigmatism index (IAI), all measured by OPD-scan III; average keratometry, corneal astigmatism, axial length, anterior chamber depth, lens thickness, and the apparent chord $\mu$ value, which is contemplated to be the distance between Purkinje image 1 and 
the apparent pupil center when viewed coaxially from the light source at the cornea, ${ }^{8,9}$ all measured by IOL M 700 .

\section{Statistical Analysis}

All categorical variables are expressed as numbers and percentages. All continuous variables are expressed using mean and $95 \%$ Confidence Interval $(95 \% \mathrm{CI})$ for the mean. Between-group analysis was performed using the KruskalWallis test adjusted for multiple comparisons, the MannWhitney $U$-test or the $X^{2}$ test, as appropriate. Three groups of glare and halos have been considered for association analyses: no vs mild vs moderate vs severe; absence vs presence; and no/mild vs moderate/severe. Four multivariate logistic regressions were performed, all with the backward conditional method, using glare and halos at 1 and 6 months as the dependent variables (groups no/mild vs moderate/severe) and age, baseline best-corrected visual acuity (BCVA) and sphere at 1 month as the independent variables. All multivariate analyses were adjusted for eye bilaterality. Tests were considered significant at $\alpha=0.05$ significance level (two-sided). SPSS v20 was used for statistical analysis.

\section{Results}

\section{Demographic Parameters}

Of the 70 patients included in this study, $57.1 \%$ were females with a mean age of 62.2 years $(95 \%$ CI 62.2 67.7). The $42.9 \%$ males showed a mean age of 66.9 years (95\% CI 64.6-69.2). There were no differences in age between sexes $(\mathrm{p}=0.396)$. When analyzing age between the different groups of glares and halos, there were some significances, all in the same direction: the lower the age the higher the glare or halos (no vs mild vs moderate vs severe, $\mathrm{p}=0.013$ for halos at 1 month; absence vs presence, $\mathrm{p}=0.038$ for glare at 1 month, $\mathrm{p}=0.003$ for halos at 1 month, $\mathrm{p}=0.012$ for glare at 6 months, $\mathrm{p}=0.032$ for halos at 6 months; and no/mild vs moderate/severe, $p=0.043$ for halos at 1 month).

\section{Capsular Opacity and Vision Quality at I and 6 Months Post-Surgery and Refractive Parameters at I Month Post-Surgery}

The incidence of capsular opacity was low both at 1 month and 6 months post-surgery ( $0.7 \%$ and $6.0 \%$, respectively). At 6 months post-surgery, 3 eyes from 2 patients showed grade 1 posterior capsular opacification (PCO) with no need for YAG laser capsulotomy, whilst 4 eyes from another 2 patients showed grade $2 \mathrm{PCO}$ and underwent YAG laser capsulotomy. Spectacle independence at all distances and at 1 and 6 months post-surgery varied between $97 \%$ and $100 \%$. Between $96.6 \%$ and $98.5 \%$ of patients would recommend the surgery. Subjective vision quality perceived by patients at 1 month varied between 9.41 and 9.75 at all distances, and at 6 months varied between 9.25 and 9.61 at all distances. As for refractive results, and 1 month after surgery, the mean sphere was 0.09 diopters (D) with a $95 \% \mathrm{CI} 0.04-0.14$, the mean cylinder was $-0.26 \mathrm{D}$ with a $95 \% \mathrm{CI}-0.29-(-0.22)$, and a mean spherical equivalent of $-0.04 \mathrm{D}$ with a $95 \% \mathrm{CI}-0.09-0.02-$ Table 1 . Also, $81.2 \%$ of eyes were within $\pm 0.25 \mathrm{D}$ and $97.1 \%$ within $\pm 0.50 \mathrm{D}$ of spherical target, whilst $96.4 \%$ of eyes were within $\leq 0.50 \mathrm{D}$ and $98.6 \%$ within $\leq 0.75 \mathrm{D}$ of cylinder.

\section{Glare and Halos at I and 6 Months Post-Surgery: Topography and Aberration Parameters}

When analyzing the 4 groups of glare and halos at 6 months, no vs mild vs moderate vs severe, patients with no halos at 6 months showed lower corneal coma when compared to patients with mild halos, with no differences on other topography or aberration parameters either for glare or halos at 6 months - Table 2 . When analyzing only between the absence vs presence of glare or halos at 6 months, patients with higher corneal coma or higher total coma showed more halos at 6 months $(\mathrm{p}=0.007$ and $\mathrm{p}=0.005$, respectively). The 0.200 to $0.399 \mu \mathrm{m}$ corneal HOA group reported less moderate halos at 1 month (28.6\%) compared to mild (69.6\%) or no $(75.0 \%)$ halos $(p=0.001)$. None of the topography or the remaining aberration parameters showed differences at 1 month.

\section{Glare and Halos at I and 6 Months Post-Surgery and Pre-Operative Biometry Parameters}

None of the pre-operative biometry parameters showed an association with glare or halos at 6 months post-surgery, when considering the 4 groups of glare or halos (no vs mild vs moderate vs severe) - Table 3 . However, when analyzing only between the absence vs presence of glare or halos at 1 month, patients with higher anterior chamber depth showed more halos at 1 month $(\mathrm{p}=0.044)$, whilst patients with higher lens thickness showed less halos at 1 month $(\mathrm{p}=0.035)$. Chord $\mu$ was higher in patients who reported halos at 1 month $(\mathrm{p}=0.007)$. 
Table I Capsular Opacity and Vision Quality at I and 6 Months Post-Surgery and Refractive Parameters at I Month Post-Surgery

\begin{tabular}{|c|c|c|c|}
\hline Parameters & $\mathbf{N}(\%)$ & Mean & $95 \% \mathrm{Cl}$ \\
\hline Capsular opacity I month $(n=140)$, yes & $\mathrm{I}(0.7)$ & $\mathrm{N} / \mathrm{A}$ & $N / A$ \\
\hline Capsular opacity 6 months $(n=116)$, yes & $7(6.0)$ & N/A & N/A \\
\hline Spectacle dependence far I month $(n=67)$, never & $66(98.5)$ & $\mathrm{N} / \mathrm{A}$ & $\mathrm{N} / \mathrm{A}$ \\
\hline Spectacle dependence intermediate I month $(n=67)$, never & $66(98.5)$ & $\mathrm{N} / \mathrm{A}$ & $N / A$ \\
\hline Spectacle dependence near I month $(n=67)$, never & $65(97.0)$ & $\mathrm{N} / \mathrm{A}$ & $\mathrm{N} / \mathrm{A}$ \\
\hline Recommend surgery I month $(n=67)$, yes & $66(98.5)$ & N/A & N/A \\
\hline Spectacle dependence far 6 months ( $n=58$ ), never & $57(98.3)$ & N/A & $\mathrm{N} / \mathrm{A}$ \\
\hline Spectacle dependence intermediate 6 months $(n=58)$, never & $58(100.0)$ & $\mathrm{N} / \mathrm{A}$ & $\mathrm{N} / \mathrm{A}$ \\
\hline Spectacle dependence near 6 months $(n=58)$, never & $57(98.3)$ & $\mathrm{N} / \mathrm{A}$ & $N / A$ \\
\hline Recommend surgery 6 months $(n=58)$, yes & $56(96.6)$ & $\mathrm{N} / \mathrm{A}$ & $\mathrm{N} / \mathrm{A}$ \\
\hline Vision quality far I month $(n=63)$ & $N / A$ & 9.41 & $9.16-9.66$ \\
\hline Vision quality intermediate I month $(n=63)$ & $N / A$ & 9.75 & $9.61-9.88$ \\
\hline Vision quality near I month $(n=63)$ & $N / A$ & 9.52 & $9.29-9.74$ \\
\hline Vision quality far 6 months $(n=56)$ & $\mathrm{N} / \mathrm{A}$ & 9.25 & $9.00-9.50$ \\
\hline Vision quality intermediate 6 months $(n=57)$ & $\mathrm{N} / \mathrm{A}$ & 9.61 & $9.46-9.77$ \\
\hline Vision quality near 6 months $(n=56)$ & $\mathrm{N} / \mathrm{A}$ & 9.46 & $9.28-9.65$ \\
\hline Sphere I month $(n=\mid 38), D$ & $N / A$ & 0.09 & $0.04-0.14$ \\
\hline Cylinder I month $(n=\mid 38), D$ & $N / A$ & -0.26 & $-0.29-(-0.22)$ \\
\hline Spherical equivalent I month $(n=\mid 38), D$ & $\mathrm{~N} / \mathrm{A}$ & -0.04 & $-0.09-0.02$ \\
\hline
\end{tabular}

Abbreviation: D, diopters.

\section{Glare and Halos at I and 6 Months Post-Surgery: Refractive and Visual Acuity Parameters}

Patients with worse pre-operative BCVA reported less glare and halos at 6 months, with different statistical significances depending on the compared groups of glare and halos (no vs mild vs moderate vs severe). Patients with mild glare at 6 months had lower 1 month spherical equivalent compared to patients with moderate glare - Table 4. Regarding glare and halos at 1 month, the same trend was observed, with patients with moderate glare or halos at 1 month having better preoperative BCVAs compared to patients with no glare or halos ( $\mathrm{p}=0.001$ and $\mathrm{p}=0.002$, respectively). When analyzing pre-operative BCVA considering only two groups of glare and halos, no/mild vs moderate/severe, there were also some significances, all in the same direction: the better the pre-operative BCVA the worse the glare or halos $(\mathrm{p}=0.042$ for halos at 1 month; $\mathrm{p}=0.026$ for glare at 6 months; $\mathrm{p}=0.003$ for halos at 6 months).

There was no correlation between pre-operative BCVA and sphere, cylinder or spherical equivalent at 1 month. There was also no association between pre-operative BCVA and spectacle dependence at all distances at 1 and 6 months.

\section{Percentage of Patients with Glare and Halos Over Time}

A significant proportion of patients had more none/mild compared to moderate/severe glare - Figure 1 - and halos - Figure 2 - both at 1 and 6 months postoperatively with no differences between time points.

\section{Predictors of Glare and Halos at I and 6 Months Post-Surgery}

After performing the multivariate logistic regressions with age, baseline BCVA and sphere at 1 month as the predictor variables, only BCVA at baseline was a negative predictor of halos at 1 month $(B=-5.363, \operatorname{Exp}(B)=0.005,95 \% C I$ for $\operatorname{Exp}(B)$ $=0.000-0.885, \mathrm{p}=0.045)$, glare at 6 months $(\mathrm{B}=-5.522, \operatorname{Exp}(\mathrm{B})$ $=0.004,95 \% \mathrm{CI}$ for $\operatorname{Exp}(\mathrm{B})=0.000-0.832, \mathrm{p}=0.043)$, and halos at 6 months $(B=-12.203, \operatorname{Exp}(B)=0.000,95 \% \mathrm{CI}$ for $\operatorname{Exp}(\mathrm{B})$ $=0.000-0.084, p=0.014)$ post-surgery. The other two variables were not significant at the end of the iteration process.

\section{Discussion}

Post-surgery refractive results were good, with a mean spherical equivalent of $-0.04 \mathrm{D}$ with a $95 \% \mathrm{CI}-0.09-0.02$, a sphere of $0.09 \mathrm{D}$ with a $95 \% \mathrm{CI} 0.04-0.14$, and a mean cylinder of $-0.26 \mathrm{D}$ with a $95 \% \mathrm{CI}-0.29-(-0.22), 1$ month after surgery. These results are supported by the subjective vision quality perceived by patients, since the mean score 
Table 2 Glare and Halos at 6 Months Post-Surgery: Topography and Aberration Parameters

\begin{tabular}{|c|c|c|c|c|c|}
\hline \multirow[b]{2}{*}{ Parameters } & \multicolumn{5}{|l|}{ Glare $(n=58)$} \\
\hline & None $(n=2 I)$ & Mild $(n=23)$ & Moderate $(n=13)$ & Severe $(n=1)$ & *p-value \\
\hline Total spherical aberration & $0.10 ; 0.04-0.17$ & $0.10 ; 0.04-0.15$ & $0.10 ; 0.04-0.16$ & $\mathrm{~N} / \mathrm{A}$ & 0.881 \\
\hline Total coma & $0.15 ; 0.10-0.19$ & $0.15 ; 0.11-0.20$ & $0.15 ; 0.08-0.21$ & $\mathrm{~N} / \mathrm{A}$ & 0.634 \\
\hline Total trefoil & $0.37 ; 0.22-0.53$ & $0.24 ; 0.13-0.35$ & $0.28 ; 0.14-0.42$ & $\mathrm{~N} / \mathrm{A}$ & 0.130 \\
\hline Total HOA & $0.5 I ; 0.32-0.7 I$ & $0.39 ; 0.27-0.51$ & $0.40 ; 0.26-0.54$ & $\mathrm{~N} / \mathrm{A}$ & 0.554 \\
\hline SRI & $0.4 I ; 0.34-0.48$ & $0.40 ; 0.31-0.49$ & $0.45 ; 0.30-0.60$ & $N / A$ & 0.608 \\
\hline$|A|$ & $0.44 ; 0.43-0.46$ & $0.43 ; 0.42-0.45$ & $0.45 ; 0.42-0.48$ & N/A & 0.527 \\
\hline Corneal spherical aberration & $0.13 ; 0.09-0.16$ & $0.13 ; 0.10-0.17$ & $0.11 ; 0.07-0.14$ & $\mathrm{~N} / \mathrm{A}$ & 0.902 \\
\hline Corneal coma & $0.13 ; 0.09-0.16$ & $0.18 ; 0.12-0.25$ & $0.13 ; 0.09-0.18$ & $\mathrm{~N} / \mathrm{A}$ & 0.673 \\
\hline Corneal trefoil & $0.17 ; 0.12-0.21$ & $0.10 ; 0.07-0.13$ & $0.11 ; 0.07-0.15$ & $\mathrm{~N} / \mathrm{A}$ & 0.073 \\
\hline \multirow[t]{2}{*}{ Corneal HOA } & $0.27 ; 0.21-0.33$ & $0.26 ; 0.20-0.33$ & $0.23 ; 0.17-0.29$ & $\mathrm{~N} / \mathrm{A}$ & 0.683 \\
\hline & \multicolumn{5}{|l|}{ Halos $(n=58)$} \\
\hline Parameters & None $(n=27)$ & Mild $(n=22)$ & Moderate $(n=9)$ & Severe $(n=0)$ & *p-value \\
\hline Total spherical aberration & $0.09 ; 0.04-0.14$ & $0.10 ; 0.04-0.15$ & $0.13 ; 0.03-0.23$ & $\mathrm{~N} / \mathrm{A}$ & 0.450 \\
\hline Total coma & $0.13 ; 0.10-0.16$ & $0.18 ; 0.12-0.23$ & $0.15 ; 0.06-0.23$ & $\mathrm{~N} / \mathrm{A}$ & 0.418 \\
\hline Total trefoil & $0.28 ; 0.21-0.35$ & $0.32 ; 0.15-0.49$ & $0.29 ; 0.09-0.48$ & $\mathrm{~N} / \mathrm{A}$ & 0.725 \\
\hline Total HOA & $0.39 ; 0.3 \mathrm{I}-0.47$ & $0.50 ; 0.29-0.70$ & $0.47 ; 0.24-0.69$ & $\mathrm{~N} / \mathrm{A}$ & 0.661 \\
\hline SRI & $0.40 ; 0.33-0.48$ & $0.43 ; 0.34-0.52$ & $0.39 ; 0.23-0.54$ & $\mathrm{~N} / \mathrm{A}$ & 0.887 \\
\hline IAI & $0.44 ; 0.43-0.45$ & $0.44 ; 0.42-0.46$ & $0.44 ; 0.40-0.47$ & $\mathrm{~N} / \mathrm{A}$ & 0.983 \\
\hline Corneal spherical aberration & $0.11 ; 0.09-0.14$ & $0.14 ; 0.11-0.17$ & $0.12 ; 0.04-0.20$ & $\mathrm{~N} / \mathrm{A}$ & 0.439 \\
\hline Corneal coma & $0.11 ; 0.09-0.13^{*}$ & $0.21 ; 0.14-0.27^{*}$ & $0.13 ; 0.05-0.21$ & $\mathrm{~N} / \mathrm{A}$ & 0.002 \\
\hline Corneal trefoil & $0.14 ; 0.10-0.18$ & $0.12 ; 0.08-0.16$ & $0.09 ; 0.06-0.13$ & $\mathrm{~N} / \mathrm{A}$ & 0.570 \\
\hline Corneal HOA & $0.24 ; 0.20-0.28$ & $0.30 ; 0.23-0.36$ & $0.22 ; 0.10-0.33$ & $\mathrm{~N} / \mathrm{A}$ & 0.197 \\
\hline
\end{tabular}

Notes: All values presented as mean; $95 \%$ Confidence Interval for mean; Significant p-values are shown in bold; *Kruskal-Wallis test adjusted for multiple comparisons. Abbreviations: HOA, higher order aberrations; SRI, corneal surface regularity index; IAI, corneal irregular astigmatism index.

Table 3 Glare and Halos at 6 Months Post-Surgery: Pre-Operative Biometry Parameters

\begin{tabular}{|c|c|c|c|c|c|}
\hline \multirow[b]{2}{*}{ Parameters } & \multicolumn{5}{|l|}{ Glare $(n=58)$} \\
\hline & None $(n=21)$ & Mild $(n=23)$ & Moderate $(n=13)$ & Severe $(n=1)$ & *p-value \\
\hline Average $\mathrm{K}$ & $43.99 ; 43.33-44.65$ & $43.81 ; 42.98-44.64$ & $43.97 ; 43.06-44.87$ & $\mathrm{~N} / \mathrm{A}$ & 0.944 \\
\hline $\mathrm{K}$ astigmatism & $0.66 ; 0.48-0.85$ & $0.59 ; 0.46-0.72$ & $0.96 ; 0.5 \mathrm{I}-\mathrm{I} .40$ & $\mathrm{~N} / \mathrm{A}$ & $0.54 I$ \\
\hline AL & $23.33 ; 22.83-23.83$ & $23.90 ; 23.42-24.38$ & $23.59 ; 22.88-24.30$ & $\mathrm{~N} / \mathrm{A}$ & 0.217 \\
\hline$A C D$ & $3.24 ; 3.06-3.42$ & $3.25 ; 3.07-3.43$ & $3.22 ; 2.99-3.44$ & $\mathrm{~N} / \mathrm{A}$ & 0.978 \\
\hline Sphere & $0.04 ;-0.74-0.81$ & $-0.18 ;-1.62-1.25$ & $0.75 ;-0.72-2.12$ & N/A & 0.342 \\
\hline Lens thickness & $4.24 ; 3.99-4.49$ & $4.35 ; 4.15-4.54$ & $4.56 ; 4.32-4.79$ & $\mathrm{~N} / \mathrm{A}$ & 0.279 \\
\hline \multirow[t]{2}{*}{ chord $\mu$} & $0.25 ; 0.18-0.31$ & $0.26 ; 0.19-0.33$ & $0.29 ; 0.18-0.41$ & $\mathrm{~N} / \mathrm{A}$ & 0.525 \\
\hline & \multicolumn{5}{|l|}{ Halos $(n=58)$} \\
\hline Parameters & None $(n=27)$ & Mild $(n=22)$ & Moderate $(n=9)$ & Severe $(n=0)$ & *p-value \\
\hline Average $\mathrm{K}$ & $43.87 ; 43.19-44.55$ & $43.89 ; 43.19-44.59$ & $44.19 ; 43.04-45.34$ & $\mathrm{~N} / \mathrm{A}$ & 0.498 \\
\hline $\mathrm{K}$ astigmatism & $0.75 ; 0.54-0.95$ & $0.64 ; 0.4 I-0.86$ & $0.7 I ; 0.42-1.01$ & $\mathrm{~N} / \mathrm{A}$ & 0.500 \\
\hline AL & $23.63 ; 23.16-24.10$ & $23.43 ; 23.0 \mathrm{I}-23.85$ & $23.92 ; 22.84-25.00$ & $\mathrm{~N} / \mathrm{A}$ & 0.569 \\
\hline$A C D$ & $3.22 ; 3.07-3.38$ & $3.21 ; 3.06-3.36$ & $3.32 ; 2.93-3.71$ & $\mathrm{~N} / \mathrm{A}$ & 0.839 \\
\hline Sphere & $0.07 ;-0.93-1.08$ & $0.5 I ;-0.66-1.68$ & $-0.53 ;-2.5 \mathrm{I}-\mathrm{I} .46$ & $\mathrm{~N} / \mathrm{A}$ & 0.469 \\
\hline Lens thickness & $4.36 ; 4.17-4.56$ & $4.39 ; 4.19-4.58$ & $4.33 ; 3.92-4.74$ & $\mathrm{~N} / \mathrm{A}$ & 0.978 \\
\hline chord $\mu$ & $0.25 ; 0.20-0.29$ & $0.32 ; 0.24-0.40$ & $0.21 ; 0.06-0.36$ & $\mathrm{~N} / \mathrm{A}$ & 0.138 \\
\hline
\end{tabular}

Notes: All values presented as mean; $95 \%$ Confidence Interval for mean; *Kruskal-Wallis test adjusted for multiple comparisons.

Abbreviations: $A L$, axial length; $A C D$, anterior chamber depth. 
Table 4 Glare and Halos at 6 Months Post-Surgery: Refractive and Visual Acuity Parameters

\begin{tabular}{|c|c|c|c|c|c|}
\hline \multirow[b]{2}{*}{ Parameters } & \multicolumn{5}{|l|}{ Glare $(n=58)$} \\
\hline & None $(n=21)$ & Mild $(n=23)$ & Moderate $(n=13)$ & Severe $(n=1)$ & p-value \\
\hline Pre-op seq & $-0.33 ;-1.13-0.47$ & $-0.46 ;-1.91-0.99$ & $0.35 ;-1.04-1.73$ & $N / A$ & 0.308 \\
\hline Pre-op BCVA & $0.21 ; 0.14-0.28 * / * *$ & $0.12 ; 0.05-0.20 *$ & $0.04 ;-0.02-0.10^{* *}$ & $N / A$ & $* 0.004 / * *<0.001$ \\
\hline I month refraction & $-0.21 ;-0.32--0.10$ & $-0.27 ;-0.36--0.19$ & $-0.27 ;-0.41--0.13$ & $\mathrm{~N} / \mathrm{A}$ & 0.610 \\
\hline I month seq & $0.02 ;-0.13-0.18$ & $-0.17 ;-0.28--0.06 *$ & $0.09 ;-0.10-0.29 *$ & $N / A$ & $* 0.001$ \\
\hline I month BCVA & $0.01 ;-0.02-0.03$ & $0.00 ;-0.02-0.01$ & $-0.0 \mathrm{I} ;-0.03-0.0 \mathrm{I}$ & $\mathrm{N} / \mathrm{A}$ & 0.942 \\
\hline \multirow[t]{2}{*}{ I month UCVA } & $0.04 ;-0.01-0.08$ & $0.02 ;-0.01-0.04$ & $0.05 ;-0.01-0.11$ & $N / A$ & $0.56 \mathrm{I}$ \\
\hline & \multicolumn{5}{|l|}{ Halos $(n=58)$} \\
\hline Parameters & None $(n=27)$ & Mild $(n=22)$ & Moderate $(n=9)$ & Severe $(n=0)$ & p-value \\
\hline Pre-op seq & $-0.29 ;-1.28-0.70$ & $0.18 ;-1.02-1.38$ & $-0.79 ;-2.89-1.30$ & $N / A$ & 0.549 \\
\hline Pre-op BCVA & $0.20 ; 0.13-0.27^{*}$ & $0.12 ; 0.06-0.18^{* *}$ & $0.00 ;-0.07-0.08^{*} / * *$ & $\mathrm{~N} / \mathrm{A}$ & $*<0.001 / * * 0.009$ \\
\hline I month refraction & $-0.20 ;-0.27--0.13$ & $-0.30 ;-0.41--0.18$ & $-0.28 ;-0.43--0.13$ & $N / A$ & 0.400 \\
\hline I month seq & $0.00 ;-0.12-0.13$ & $-0.14 ;-0.26--0.01$ & $0.03 ;-0.25-0.31$ & $\mathrm{~N} / \mathrm{A}$ & 0.171 \\
\hline I month BCVA & $0.01 ;-0.01-0.03$ & $-0.0 \mathrm{I} ;-0.02-0.00$ & $-0.01 ;-0.04-0.01$ & N/A & 0.410 \\
\hline I month UCVA & $0.05 ; 0.01-0.08$ & $0.0 \mathrm{I} ;-0.0 \mathrm{I}-0.03$ & $0.03 ;-0.05-0.12$ & $N / A$ & 0.415 \\
\hline
\end{tabular}

Notes: All values presented as mean; $95 \%$ Confidence Interval for mean; p-values from Kruskal-Wallis test adjusted for multiple comparisons. Significant p-values are shown in bold; *Groups significantly different from each other; **Groups significantly different from each other.

Abbreviations: seq, spherical equivalent; pre-op, pre-operative; BCVA, best-corrected visual acuity in LogMAR; UCVA, uncorrected visual acuity in LogMAR.

at 1 month varied between 9.41 and 9.75 at all distances, and at 6 months varied between 9.25 and 9.61 at all distances (Table 1). Spectacle independence at all distances and at 1 and 6 months post-surgery varied between $97 \%$ and $100 \%$, and probably for this reason between $96.6 \%$ and $98.5 \%$ of patients would recommend the surgery (Table 1). The incidence of capsular opacity was low both at 1 month and 6 months post-surgery $(0.7 \%$ and
$6.0 \%$, respectively). At 6 months post-surgery, 3 eyes from 2 patients showed grade $1 \mathrm{PCO}^{10}$ with no need for YAG laser capsulotomy, whilst 4 eyes from another 2 patients showed grade $2 \mathrm{PCO}^{10}$ and underwent $\mathrm{YAG}$ laser capsulotomy. PCO had no influence on visual acuity or on the occurrence of glare or halos.

In our study, patients who presented a better baseline BCVA were more prone to perceive glares and halos after

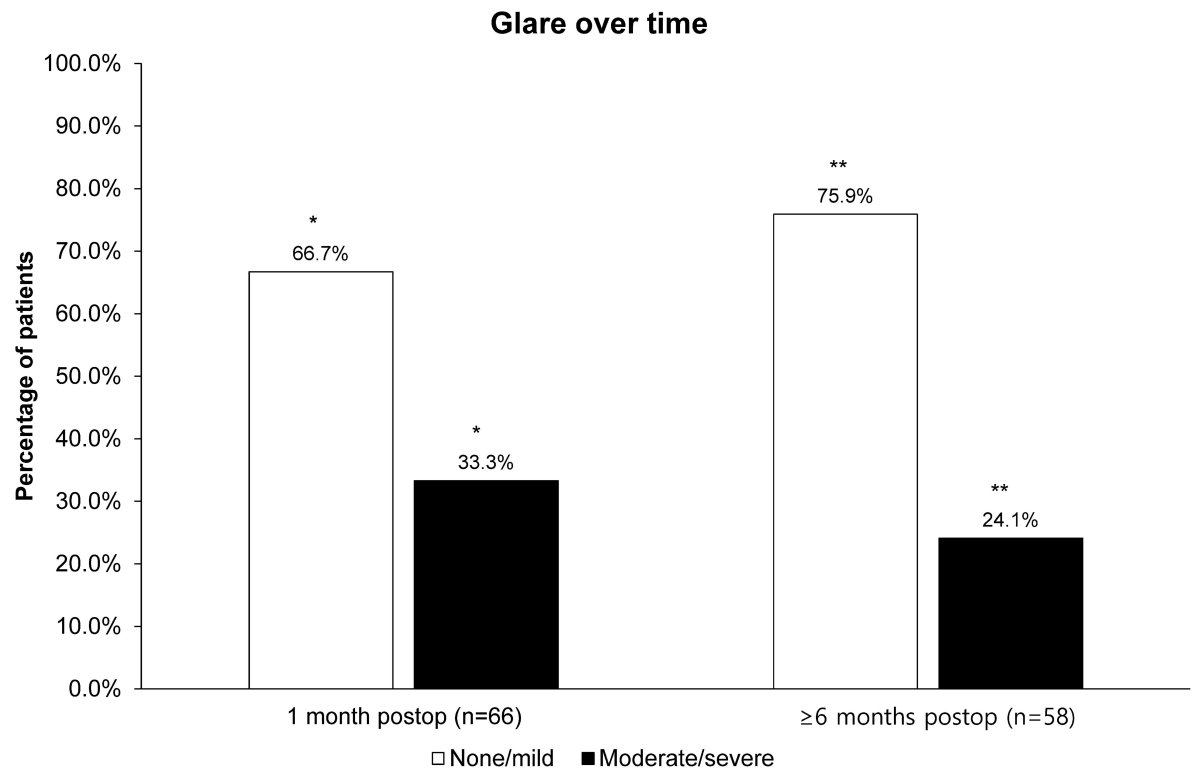

Figure I Percentage of patients with glare over time. $* / * * p=0.001 . p=n$ s between time points. 


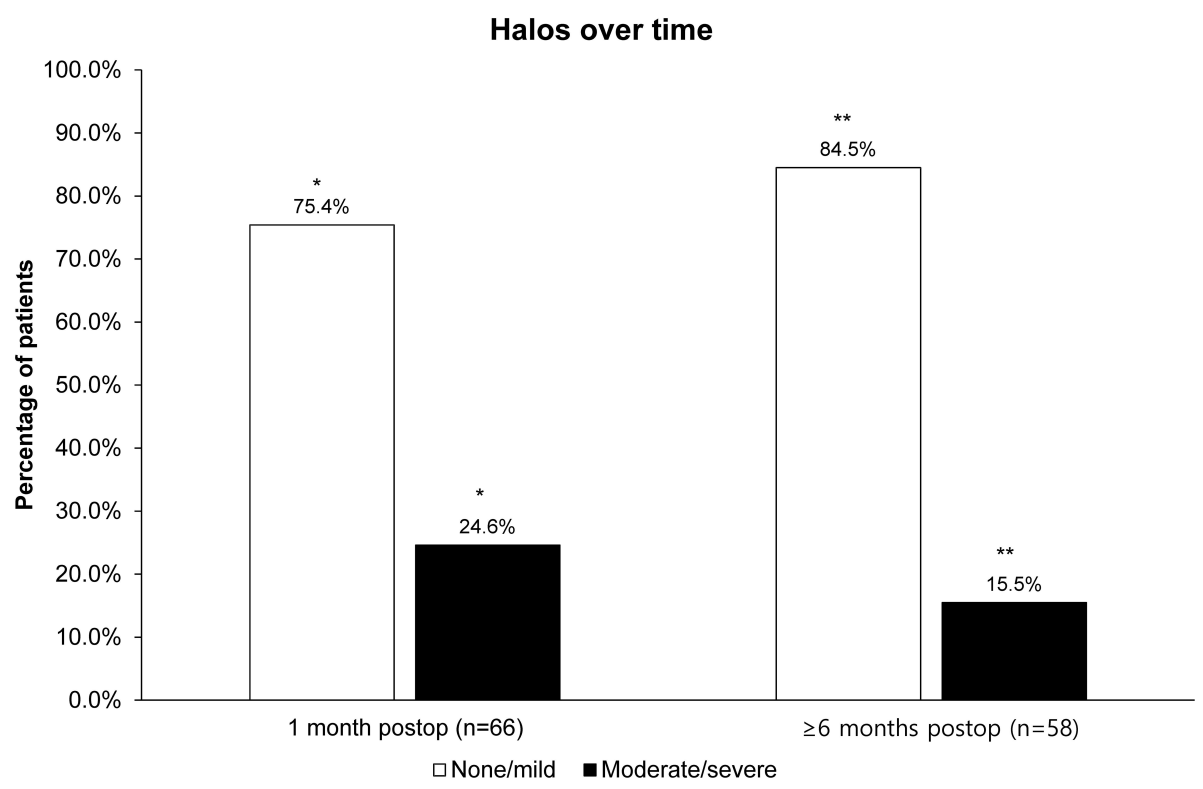

Figure 2 Percentage of patients with halos over time. $* * * * p=0.002 . p=n s$ between time points.

1 month of surgery in comparison with the ones with a worse baseline BCVA. The same results were observed 6 months after surgery. Since the residual refractive error after surgery was very low and there was no correlation between pre-operative BCVA and sphere, cylinder or spherical equivalent at 1 month, and no association between pre-operative BCVA and spectacle dependence at all distances at 1 and 6 months, the relationship between preoperative visual acuity and photic phenomena was not influenced by any of the mentioned results. Thus, the association between baseline BCVA and glares and halos seems to be dependent solely on the patient's perception.

Overall, regression analysis corroborated the causality relation between a better baseline visual acuity and the occurrence of photic phenomena suggested by association analyses. These suggest that patients that have a better visual acuity before surgery are more demanding regarding visual outcomes after surgery, unlike those who have more visual impairment and therefore perceive any small improvement as important.

It has been proposed that perceived understanding of post-operative function and expectation-outcome discrepancy are important factors in the overall satisfaction of intervened cataract patients that generally present high expectations concerning the results of the procedures. ${ }^{11}$ Subjective visual symptoms, mostly blurred vision and photic phenomena, have been reported as the leading causes of patient dissatisfaction after multifocal IOL implantation, even though good visual acuity outcomes are obtained. ${ }^{12}$ Tchah et al suggested that visual acuity may not always be a good measure of subjective symptoms or patient satisfaction following implantation of multifocal IOL, since it was noticed that although all dissatisfied subjects had subjective visual complaints, their corrected distance visual acuity was $20 / 20$ or better. $^{5}$

Welch et al illustrated that the general level of patient satisfaction regarding cataract removal and IOL placement, while high, is still more affected by glare than by any other studied parameter, including UDVA, BCVA, posterior capsular opacification, and anterior capsular overlap of the IOL optic. ${ }^{13}$

Concerning the Acrysof $\mathrm{IQ}^{\circledR}{ }^{\circledR}$ PanOptix ${ }^{\circledR}$, a study in 116 eyes of 58 patients evaluated visual outcomes with a visual satisfaction questionnaire (Catquest 9-SF with 5 added questions), which included photic phenomena, 9 and 12 months after surgery. A high percentage of patients did not present daily life challenges (84.5\%), in spite of $32.8 \%$ reporting seeing halos often or always with illumination and $10.3 \%$ having occurrences of glare. Only 3.4\% of patients declared to be quite unsatisfied with the surgery. ${ }^{14}$ Another study compared the visual performance and quality of vision of 60 binocularly implanted trifocal IOLs (FineVision vs PanOptix). Once again, halos were the most common phenomenon reported by patients, being mostly mild and therefore not considered to impact quality of life significantly. ${ }^{15}$ 
It has been suggested that glare and halos reported by pseudophakic patients can be attributed to spherical aberration. The contrast sensitivity anticipated for a multifocal IOL is lower than for healthy eyes, due to the increase in spherical aberration, and post-operative loss of contrast sensitivity after multifocal IOL implantation has been associated to HOA increase. ${ }^{16}$ The fact that the 0.200 to $0.399 \mu \mathrm{m}$ corneal HOA group reported less moderate halos at 1 month compared to mild or no halos may indicate that patients within this range of HOA present a better visual quality and, therefore, less photic phenomena.

Our results also showed that both corneal coma and total coma are associated with mild halos at 6 months, which indicates that the lower the coma, the less the possibility of the occurrence of mild halos at 6 months. Univariate analysis, which considered corneal and total coma groups, showed the same results for the lower coma group, $0.000-0.199 \mu \mathrm{m}$.

Despite many patients with high angle kappa being asymptomatic, statistically significant association of angle kappa with the occurrence of halos and glares has been reported in some studies. ${ }^{17,18}$ Our results did not show any association between angle kappa and glare or halos. One possible explanation could be the cut-off value we have selected for the angle kappa in the inclusion criteria $(\leq 0.58 \mathrm{~mm})$. This is the value of the radius of the inner circle of the diffractive zone of the PanOptix trifocal IOL. It has been suggested that if the eye has an angle kappa greater than half of the diameter of the central ring of the multifocal IOL, light rays may pass through one or more of the multifocal rings and produce glare. ${ }^{19}$

Our results also suggest that the higher the lens thickness the less the occurrence of halos at 1 month. A higher value of chord $\mu$ was associated with a higher incidence of halos at 1 month, with no differences at 6 months or glare at any time point. The reported mean value and standard deviation for apparent chord $\mu$ is $0.30 \pm 0.15 \mathrm{~mm}$. We may speculate that this absence of statistical significance may be due to the fact that in our study only one patient showed a chord $\mu$ value $>0.6 \mathrm{~mm}$ and it has been suggested that values higher than $0.6 \mathrm{~mm}$ are more likely related to glare and halos with diffractive multifocal IOLs. ${ }^{20-22}$

Finally, age was associated with glare and halos at 1 and 6 months: lower aged patients showed more glare and halos at 1 month and 6 months. Similar results regarding halos in younger patients were published with the implantation of another trifocal IOL. ${ }^{23}$ Again these results suggest that lower aged patients are more demanding regarding visual outcomes after surgery. However, another study analyzed refractive and visual outcomes, patient satisfaction, and complications among different age groups. There were no statistically significant differences in visual phenomena or night driving difficulties reported by patients of different age groups. ${ }^{24}$

This study had some limitations. It was a single-center study, with no control group, and the time of follow-up might not have been sufficient to completely understand the level of bothersome related to unwanted photic phenomena, since its perception tends to decrease with time. It has been shown by the use of functional magnetic resonance imaging (MRI) that after the implantation of multifocal IOLs a form of long-term adaptation/functional plasticity occurs, since the study showed that fewer brain regions were required to perform the visual tasks as time passed. ${ }^{25}$ The main strengths of this study are the fact that all surgeries were performed by the same surgeon, thus reducing variability, and the fact that both objective and subjective parameters were collected.

\section{Conclusion}

This study shed some light on predictive factors of dissatisfaction for photic phenomena, allowing for a better management of patients' expectations and increased satisfaction with the procedure. On multivariate regression analyses the only predictor of photic phenomena was baseline visual acuity, suggesting that patients that have a better visual acuity before surgery are more demanding regarding visual outcomes after surgery, unlike those who have more visual impairment and therefore perceive any small improvement as important.

\section{Acknowledgments}

There are no acknowledgements.

\section{Author Contributions}

All authors made a significant contribution to the work reported, whether that is in the conception, study design, execution, acquisition of data, analysis and interpretation, or in all these areas; took part in drafting, revising or critically reviewing the article; gave final approval of the version to be published; have agreed on the journal to which the article has been submitted; and agree to be accountable for all aspects of the work. 


\section{Funding}

This research did not receive any specific grant from funding agencies in the public, commercial, or not-forprofit sectors.

\section{Disclosure}

The authors have no conflicts of interest to declare.

\section{References}

1. de Silva SR, Evans JR, Kirthi V, Ziaei M, Leyland M. Multifocal versus monofocal intraocular lenses after cataract extraction Cochrane Database Syst Rev. 2016;12:Cd003169. doi:10.1002/ 14651858.CD003169.pub4

2. Khandelwal SS, Jun JJ, Mak S, Booth MS, Shekelle PG. Effectiveness of multifocal and monofocal intraocular lenses for cataract surgery and lens replacement: a systematic review and meta-analysis. Graefes Arch Clin Exp Ophthalmol. 2019;257 (5):863-875. doi:10.1007/s00417-018-04218-6

3. Buckhurst PJ, Naroo SA, Davies LN, Shah S, Drew T, Wolffsohn JS. Assessment of dysphotopsia in pseudophakic subjects with multifocal intraocular lenses. BMJ Open Ophthalmol. 2017;1(1):e000064. doi:10.1136/bmjophth-2016-000064

4. Lee S, Choi M, Xu Z, Zhao Z, Alexander E, Liu Y. Optical bench performance of a novel trifocal intraocular lens compared with a multifocal intraocular lens. Clin Ophthalmol. 2016;10:1031-1038. doi:10.2147/OPTH.S106646

5. Tchah H, Nam K, Yoo A. Predictive factors for photic phenomena after refractive, rotationally asymmetric, multifocal intraocular lens implantation. Int J Ophthalmol. 2017;10(2):241-245. doi:10.18240/ ijo.2017.02.10

6. Kohnen T. First implantation of a diffractive quadrafocal (trifocal) intraocular lens. J Cataract Refract Surg. 2015;41(10):2330-2332. doi:10.1016/j.jcrs.2015.11.012

7. Kohnen T, Herzog M, Hemkeppler E, et al. Visual performance of a quadrifocal (trifocal) intraocular lens following removal of the crystalline lens. Am J Ophthalmol. 2017;184:52-62. doi:10.1016/j. ajo.2017.09.016

8. Narang P, Agarwal A Chord mu: a new reference marker and its clinical relevance. Ocular Surgery News U.S. Edition; October 10 , 2019. Available from: https:/www.healio.com/ophthalmology/refrac tive-surgery/news/print/ocular-surgery-news/\%7B61 df24dc-e212 -4f97-9b48-95ae4469aa2d\%7D/chord-mu-a-new-reference-markerand-its-clinical-relevance. Accessed January 7, 2021.

9. Holladay JT. Apparent chord mu and actual chord mu and their clinical value. J Cataract Refract Surg. 2019;45(8):1198-1199. doi:10.1016/j.jcrs.2019.03.029

10. Shakeel T, Dasgupta S. Comparative evaluation of posterior capsular opacification and Nd: YAG capsulotomy in children and adults. J Clin Exp Ophthalmol. 2019;5:105-107.
11. Chen Z, Lin X, Qu B, et al. Preoperative expectations and postoperative outcomes of visual functioning among cataract patients in Urban Southern China. PLoS One. 2017;12(1):e0169844. doi:10.1371/journal.pone.0169844

12. de Vries NE, Webers CAB, Touwslager WRH, et al. Dissatisfaction after implantation of multifocal intraocular lenses. $J$ Cataract Refract Surg. 2011;37(5):859-865. doi:10.1016/j.jcrs.2010.11.032

13. Welch NR, Gregori N, Zabriskie N, Olson RJ. Satisfaction and dysphotopsia in the pseudophakic patient. Can $J$ Ophthalmol. 2010;45(2):140-143. doi:10.3129/i09-266

14. Garcia-Perez JL, Gros-Otero J, Sanchez-Ramos C, Blazquez V, Contreras I. Short term visual outcomes of a new trifocal intraocular lens. BMC Ophthalmol. 2017;17(1):72. doi:10.1186/s12886-017-0462-y

15. Gundersen KG, Potvin R. Trifocal intraocular lenses: a comparison of the visual performance and quality of vision provided by two different lens designs. Clin Ophthalmol. 2017;11:1081-1087. doi:10.2147/ OPTH.S136164

16. Bellucci R, Curatolo MC, New Extended A. Depth of focus intraocular lens based on spherical aberration. J Refract Surg. 2017;33 (6):389-394. doi:10.3928/1081597X-20170329-01

17. Fu Y, Kou J, Chen D, et al. Influence of angle kappa and angle alpha on visual quality after implantation of multifocal intraocular lenses. $J$ Cataract Refract Surg. 2019;45(9):1258-1264. doi:10.1016/j. jcrs.2019.04.003

18. Wang R, Long T, Gu X, Ma T. Changes in angle kappa and angle alpha before and after cataract surgery. $J$ Cataract Refract Surg. 2020;46(3):365-371. doi:10.1097/j.jcrs.0000000000000063

19. Moshirfar M, Hoggan RN, Muthappan V. Angle Kappa and its importance in refractive surgery. Oman J Ophthalmol. 2013;6 (3):151-158. doi:10.4103/0974-620X.122268

20. Prakash G, Prakash DR, Agarwal A, Kumar DA, Agarwal A, Jacob S. Predictive factor and kappa angle analysis for visual satisfactions in patients with multifocal IOL implantation. Eye (Lond). 2011;25(9):1187-1193. doi:10.1038/eye.2011.150

21. Karhanová M, Marešová K, Pluháček F, Mlčák P, Vláčil O, Sín M The importance of angle kappa for centration of multifocal intraocular lenses. Cesk Slov Oftalmol. 2013;69(2):64-68.

22. Karhanová M, Pluháček F, Mlčák P, Vláčil O, Šín M, Marešová K. The importance of angle kappa evaluation for implantation of diffractive multifocal intra-ocular lenses using pseudophakic eye model. Acta Ophthalmol. 2015;93(2):e123-e128. doi:10.1111/aos.12521

23. Vryghem JC, Heireman S. Visual performance after the implantation of a new trifocal intraocular lens. Clin Ophthalmol. 2013;7:1957-1965. doi:10.2147/OPTH.S44415

24. Schallhorn SC, Schallhorn JM, Pelouskova M, et al. Refractive lens exchange in younger and older presbyopes: comparison of complication rates, 3 months clinical and patient-reported outcomes. Clin Ophthalmol. 2017;11:1569-1581. doi:10.2147/OPTH.S143201

25. Rosa AM, Miranda AC, Patricio MM, et al. Functional magnetic resonance imaging to assess neuroadaptation to multifocal intraocular lenses. J Cataract Refract Surg. 2017;43(10):1287-1296. doi:10.1016/j.jcrs.2017.07.031
Clinical Ophthalmology

\section{Publish your work in this journal}

Clinical Ophthalmology is an international, peer-reviewed journal covering all subspecialties within ophthalmology. Key topics include: Optometry; Visual science; Pharmacology and drug therapy in eye diseases; Basic Sciences; Primary and Secondary eye care; Patient Safety and Quality of Care Improvements. This journal is indexed on PubMed
Central and CAS, and is the official journal of The Society of Clinical Ophthalmology (SCO). The manuscript management system is completely online and includes a very quick and fair peer-review system, which is all easy to use. Visit http://www.dovepress.com/ testimonials.php to read real quotes from published authors. 